\title{
Early Versus Delayed Laparoscopic Cholecystectomy in Mild Acute Biliary Pancreatitis. A Comparative Study
}

\author{
Abd El Aziz $M^{1^{*}}$, Zidan $A^{2}$, El Khawas $M^{1}$, El Sherbiny $A^{1}$, El Bahy $A^{1}$, Shoma $A^{1}$, El Moghazy $M^{1}$, \\ Burham $\mathbf{W}^{1}$ \\ ${ }^{I}$ General Surgery Department, Mansoura University Hospitals, Mansoura University, Egypt \\ ${ }^{2}$ Hepatobiliary Surgery Department, Theodor Bilharz Research Institute, El Warraq, Egypt
}

*Corresponding Author: Mahmoud Abdel Aziz El Sayed Hamed, Lecturer of surgery, Faculty of Medicine Mansoura University, Egypt, Email: azizmahmoud84.ma@gmail.com

\begin{abstract}
Background: Acute biliary pancreatitis is a critical surgical emergency that requires inpatient conservative management. Cholecystectomy is planned for those patients to avoid recurrent attacks. On the contrary of management of acute cholecystitis early cholecystectomy during the same admission after resolution of the acute pancreatitis is the key for prevention of recurrence and prevention more complications.

Patients and Methods: Between Nov 2017 - Nov 2018, sixty patients with mild acute biliary pancreatitis were included in this study randomized in two groups. First group (30 patients) underwent laparoscopic cholecystectomy after 48 hours of admission, the second group (30 patients) was discharged home after management of acute pancreatitis and laparoscopic cholecystectomy was planned after six weeks. Intra, postoperative complications, conversion rate and recurrent biliary events were compared in both groups.
\end{abstract}

Results: There was no significant difference in intra or postoperative complications or conversion to open rate in both groups. Recurrent biliary problems were highly reported in the delayed group.

Conclusion: Early cholecystectomy in mild acute biliary pancreatitis during the same admission is safe, feasible and prevent recurrent biliary complications.

\section{INTRODUCTION}

Acute pancreatitis is considered one of the critical emergency conditions that necessitate inpatient admission because of its deleterious complications. Variable causes including, gall bladder stones, hyperlipidemia and alcohol consumption are the commonest. $(1,2)$

Biliary pancreatitis (BP) or gallstone pancreatitis, is a frequent cause of acute pancreatitis (AP) accounting for $40-50 \%$ and may reach up to $70 \%$ of the cases especially in developed countries. (3)

The main pathogenesis of biliary pancreatitis is caused by gallstones migration that leads to either bile, pancreatic or both duct obstruction. This obstruction increase the intraductal pressure with subsequent disturbance of pancreatic digestive enzymes. (4)

Most of attacks of mild biliary pancreatitis resolve itself within one week without serious complications but leaving the gall stones in place will lead to high incidence of recurrence up to $90 \%$ that may lead to more complications. $(5,6)$

Cholecystectomy is the main stay of treatment in biliary pancreatitis to avoid the high recurrence rate. Timing of cholecystectomy in mild BP is still a matter of debate among surgeons. (5)

Although The British Society of Gastroenterology recommended definitive treatment of mild biliary pancreatitis by cholecystectomy during the same hospital admission (7), a study in England showed that only one third of the patients underwent early cholecystectomy during the same admission. This also was observed in USA and Europe. (8, 9)

Many factors may contribute this contradiction, risk of intraoperative complications because of 
hostile field, non availability of sufficient emergency theatre capacity, surgical resources and also the great advent of ERCP that reduce the risk of recurrence of biliary pancreatitis after sphincterotomy. (10)

\section{Patients And Methods}

In the period between (November 2017 November 2018). 60 patients with mild acute biliary pancreatitis were enrolled in this randomized controlled trial after a written informed consent.

Exclusion criteria were: age $<18$ and $>60$ years, severe cardiopulmonary disease severe pancreatitis and obstructive jaundice or cholangitis.

Acute pancreatitis was diagnosed when the patient has acute upper abdominal pain with elevated serum amylase/lipase more than 3 times of upper normal range.

Severity was assessed according to Atlanta classification 2012.

After detailed clinical examination, routine laboratory investigations were done.

All patients had abdominal ultrasound to confirm presence of gall bladder stones.

Conservative measures was started (IV fluid, proton pump inhibitors and paracetamol injection).

Patients were randomized into two groups using closed envelop technique:

Group A: (30) patients who underwent laparoscopic cholecystectomy after 48 hours from day of admission.

Group B: (30) patients who discharged home after resolution of the acute phase and underwent laparoscopic cholecystectomy after 6 weeks.
Both groups were compared as regard: operative time, intraoperative findings and complications, conversion to open surgery, use of abdominal drains, hospital stay, post operative complications, readmission after discharge.

All patients' data were collected, checked and analyzed by using (SPSS version 22). Data were expressed as mean \pm standard deviation (SD) and number with (\%) according to type of variable. Chi-square test $\left(\chi^{2}\right)$ or Fischer's exact t test or Mann-Whitney were used when appropriate. $\mathrm{P}$ value $<0.05$ was considered statistically significant.

\section{Results}

Sixty consecutive patients with mild acute biliary pancreatitis were prospectively randomized into two groups:

Group A: early 48 h laparoscopic cholecystectomy

Group B: laparoscopic cholecystectomy after six weeks.

The mean age of patients in group A was 35.67 \pm 12.96 y (range $=20-57 \mathrm{y})$ while in group $\mathrm{B}$ was $36.73 \pm 12.06$ y $($ range $=20-55 \mathrm{y})$.

The vast majority of the patients were female. 19 patients $(63.3 \%)$ in group A and 25 patients $(83.3 \%)$ in group B.

\subsection{Operative Time}

A significant differences in the operative time between both groups were shown in table (1) using a Mann Whitney $\mathrm{Z}$ test. In group $\mathrm{A}$ the operative time ranged from 45 minutes to 90 minutes with a mean of 67.00 minutes (SD \pm 15.62 ), while in group B operative time ranged from 40 minutes to 75 minutes with a mean of 57.00 minutes $(\mathrm{SD} \pm 11.58)$. $\mathrm{P}$ value was significant 0.010 .

Table1. Operative time

\begin{tabular}{|c|c|c|c|}
\hline Operative parameter & Group A & Group B & Test \\
\hline \multicolumn{3}{|l|}{ Operative time (min) } & \multirow{5}{*}{$Z=2.676^{*}$} \\
\hline - Minimum & 45 & 40 & \\
\hline - Maximum & 90 & 75 & \\
\hline - Mean & 67.00 & 57.00 & \\
\hline$-\mathrm{SD} \pm$ & 15.62 & 11.58 & \\
\hline
\end{tabular}

\subsection{Intraoperative Findings}

In group A 3 patients (10\%) have intraoperative finding of acute cholecystitis where as none of group B express acute cholecystitis intraoperatively, with no statistically difference ( $\mathrm{p}$ value 0.076) Table (2) 
Early Versus Delayed Laparoscopic Cholecystectomy in Mild Acute Biliary Pancreatitis. A Comparative Study

Table2. Intraoperative findings

\begin{tabular}{|c|c|c|c|c|c|c|}
\hline \multirow[t]{3}{*}{ Intraoperative findings } & \multicolumn{4}{|c|}{ Group } & \multirow[t]{3}{*}{$\chi^{2}$} & \multirow[t]{3}{*}{$\mathbf{P}$} \\
\hline & \multicolumn{2}{|r|}{ A } & \multicolumn{2}{|r|}{ B } & & \\
\hline & No & $\%$ & No & $\%$ & & \\
\hline \multicolumn{7}{|l|}{ Acute cholecystitis } \\
\hline No & 27 & $90.0 \%$ & 30 & $100.0 \%$ & \multirow[t]{2}{*}{3.158} & \multirow[t]{2}{*}{0.076} \\
\hline Yes & 3 & $10.0 \%$ & 0 & $0.0 \%$ & & \\
\hline
\end{tabular}

\subsection{Intraoperative Complications}

There were no major intraoperative complications like bowel injury, major blood vessels or major biliary injury. The main intraoperative unfavorable events that had occurred during surgery encompassed three

Table3. Intraoperative complications

\begin{tabular}{|c|c|c|c|c|c|c|}
\hline & \multicolumn{2}{|c|}{ Group A } & \multicolumn{2}{|c|}{ Group B } & \multirow[t]{2}{*}{$\chi^{2}$} & \multirow[t]{2}{*}{$\mathbf{P}$} \\
\hline & No & $\%$ & No & $\%$ & & \\
\hline \multicolumn{5}{|c|}{ Intraoperative complications } & \multirow{7}{*}{5.400} & \multirow{7}{*}{0.145} \\
\hline No events & 21 & $70.0 \%$ & 21 & $70.0 \%$ & & \\
\hline Gall bladder perforation & 6 & $20.0 \%$ & 4 & $13.3 \%$ & & \\
\hline Bleeding from liver bed & 3 & $10.0 \%$ & 1 & $3.3 \%$ & & \\
\hline Bleeding from port site & 0 & $0.0 \%$ & 4 & $13.3 \%$ & & \\
\hline Use of drains & 1 & $3.3 \%$ & 0 & $0.0 \%$ & & \\
\hline Major events & 0 & $0.0 \%$ & 0 & $0.0 \%$ & & \\
\hline
\end{tabular}

\subsection{Conversion to Open Repair}

All the cases were completed laparoscopically none of them were converted to open cholecystectomy in both groups.

\subsection{Recurrent Biliary Problems}

None of the patients underwent early cholecystectomy has recurrent biliary issues $(0 \%)$. Thirteen patients $(43.33 \%)$ in the delayed group had gallstone-related problems during the

Table4. Recurrent biliary event main complications: gallbladder perforation, bleeding from the liver bed and port site bleeding. As shown in table (3) There was no significant difference in intraoperative complications between both groups.

\begin{tabular}{|c|c|c|c|c|c|}
\hline & \multicolumn{4}{|c|}{ Groups } & \multirow[t]{3}{*}{$\mathbf{P}$} \\
\hline & \multicolumn{2}{|c|}{$\mathbf{A}$} & \multicolumn{2}{|c|}{ B } & \\
\hline & No & $\%$ & No & $\%$ & \\
\hline Recurrent biliary events & \multicolumn{2}{|c|}{ No events } & 13 & 43.33 & \multirow[t]{4}{*}{$<0.0001$} \\
\hline Biliary colic & 0 & $0 \%$ & 8 & $26.66 \%$ & \\
\hline Acute cholecystitis & 0 & $0 \%$ & 2 & $6.66 \%$ & \\
\hline Recurrent biliary pancreatitis & 0 & $0 \%$ & 3 & $10.0 \%$ & \\
\hline
\end{tabular}

\subsection{Total Length of Hospital Stay}

The total length of stay (LOS) (which includes the index admission plus admission for precholecystectomy recurrences plus admission for cholecystectomy) is longer in group B compared with group $\mathrm{A}$. In the B group, median total LOS is 9 days whereas it is 8 days in the $A$ group (p 0.002). (Table 5)

Table5. Total length of hospital stay

\begin{tabular}{|lc|c|c|c|}
\hline & Group A & Group B & P \\
\hline $\begin{array}{l}\text { Total Length of } \\
\text { hospital stay }\end{array}$ & $\begin{array}{c}7(5-9) \\
\text { days }\end{array}$ & $\begin{array}{c}9(8-11) \\
\text { days }\end{array}$ & $\mathbf{0 . 0 0 2}$ \\
\hline
\end{tabular}

interval between resolution of the acute pancreatitis and delayed cholecystectomy Table (4). The difference between the two groups is significant $(0 \%$ vs. $43.33 \%, \mathrm{p}<0.0001)$. Five patients $(16.6 \%)$ required hospital readmission due to severity of the symptoms. Eight patients (26.66\%) had biliary colic, two patients $(6.66 \%)$ developed acute cholecystitis, and three patients $(10 \%)$ had recurrent biliary pancreatitis.

\section{DISCUSSION}

For several decades surgeons believed that laparoscopic cholecystectomy in acute biliary pancreatitis during index of admissionis a risky procedure and associated with high risk of morbidities and complications. This is well established now in severe episodes of acute pancreatitis because of extensive edema and local complications.(11) Sanjay et al (12) concluded that delayed interval cholecystectomy is more safe and associated with less morbidities and readmission. 
In mild pancreatitis however many studies were published about optimal timing for cholecystectomy, limited randomized clinical trials were available. Till now despite of some guidelines and recommendations, there no consensus it is safe or not to discharge patients with mild pancreatitis before doing cholecystectomy. $(13,14,15,16)$

Recent studies and meta analyses concluded that delayed cholecystectomy had no advantages over the early intervention as regard intra and post operative complications. In our current study early cholecystectomy did not add any complications or morbidities to the patients compared with delayed ones. $(17,18,19)$

Although duration of surgery in delayed group was less than the early group in our study, there was no significant differences in intraoperative complications and the conversion rate was the same in both groups.

Dacosta et al., Noel et al., and Omar et al, found no significant difference in intraoperative complications in between early and delayed cholecystectomy. $(20,21,22)$

In delayed cholecystectomy the patients had high risk of biliary symptoms that in some circumstances necessitate inpatient admission as acute cholecystitis or recurrent pancreatitis.

Van Baal et al, (17) Bakker et al (23) and Ito et al.(24) have suggested that there is a substantial risk of recurrent biliary events after discharge from hospital following an episode of acute biliary pancreatitis and before interval cholecystectomy

Johnstone et al, (19) Randial et al, (18) Wilson et al (25) and Alimoglu etal,(26) reported high incidence of recurrent biliary events $9-60 \%$ in delayed cholecystectomy patients. Shir Li Jee et al(3) reported recurrent biliary issues in $44 \%$ in delayed group.

In our study, $43.3 \%$ of the patients in delayed group developed recurrent biliary problems prior to delayed cholecystectomy, $16.6 \%$ required hospital admission.

Ito et al (24) have suggested that two weeks interval prior to cholecystectomy is considered too long because nearly $30 \%$ of recurrence occurs in the first 2 weeks after discharge, Shir li Jee et al (3) also reported 27\% of recurrence in the first 2 weeks.
In our study, Patients who underwent early cholecystectomy had short hospital stay when compared to the other delayed group. This significant difference may be attributed to recurrent hospital admission in delayed group $(16.6 \%)$ which has also a great economic impact.

Rosing et al (27) and Shir li Jee etal, (3) found that early cholecystectomy was associated with a significantly shorter length of hospital stay when compared with the delayed group ( $\mathrm{p} \mathrm{Z}$ 0.0016). With no increase in complications or mortality.

\section{CONCLUSION}

This study showed that early cholecystectomy in patients with mild acute biliary pancreatitis has no added risk of intra or post operative complications than delayed cholecystectomy. Also it significantly reduces the risk of recurrent biliary problems and length of hospital stay which has a great impact on the patients and health care resources .

\section{REFERENCES}

[1] Adiamah A, Psaltis E, Crook M, et al. A systematic review of the epidemiology, pathophysiology and current management of hyperlipidaemic pancreatitis. Clin Nutr 2018; 37(Part A): 1810-1822.

[2] Spanier BW, Dijkgraaf MG and Bruno MJ. Epidemiology, aetiology and outcome of acute and chronic pancreatitis: an update. Best Pract Res Clin Gastroenterol 2008; 22: 45-63.

[3] Shir Li Jee, Razman Jarmin B , Kin Foong $\operatorname{Lim}$ A, et al. Outcomes of early versus delayed cholecystectomy in patients with mild to moderate acute biliary pancreatitis: A randomized prospective study. Asian journal of surgery(2018) 41, 47-54.

[4] Guo-Jun Wang, Chun-Fang Gao, Dong Wei, et al. Acute pancreatitis: Etiology and common pathogenesis. World J Gastroenterol 2009 March 28; 15(12): 1427-1430.

[5] Tom K. Lin, Joseph J. Palermo, y Jaimie D. Nathan, et al. Timing of Cholecystectomy in Children With Biliary Pancreatitis. (JPGN 2016;62: 118-121) .

[6] Kelly TR and Swaney PE. Gallstone pancreatitis: the second time around. Surgery 1982;92:571-575.

[7] Toouli J, Brooke-Smith M, Bassi C, et al. Guidelines for the management of acute pancreatitis. J Gastroenterol Hepatol. 2002:17. Suppl:S15-39.

[8] El-Dhuwaib Y, Deakin M, David GG, et al. Definitive management of gallstone pancreatitis 
in England. Ann R Coll Surg Engl 2012; 94: 402-406.

[9] Bakker OJ, van Santvoort HC, Hagenaars JC, et al. Dutch Pancreatitis Study Group. Timing of cholecystectomy after mild biliary pancreatitis. Br J Surg 2011; 98: 1446-1454.

[10] N. Moody, A. Adiamah, F. Yanni and D. Gomez. Meta-analysis of randomized clinical trials of early versus delayed cholecystectomy for mild gallstone pancreatitis. BJS 2019; 106: 1442-1451.

[11] Nealon WH, Bawduniak J and Walser EM. Appropriate timing of cholecystectomy in patients who present with moderate to severe gallstone-associated acute pancreatitis with peripancreatic fluid collections. Ann Surg. 2004;239(6):741-749. discussion 49-51.

[12] Sanjay P, Yeeting S, Whigham $\mathbf{C}$, et al. Endoscopic sphincterotomy and interval cholecystectomy are reasonable alternatives to index cholecystectomy in severe acute gallstone pancreatitis (GSP). Surg Endosc. 2008; 22(8):1832-1837.

[13] I W, Warshaw A, Imrie C, et al. IAP Guidelines for the Surgical Management of Acute

[14] Forsmark CE and Baillie J. AGA Institute technical review on acute pancreatitis. Gastroenterology. 2007;132(5):2022-2044.

[15] Tennet S, Bailie J, DeWitt J, et al. American College of Gastroenterology Guideline: management of acute pancreatitis. Am J Gastroenterol. 2013. http://dx.doi.org/10.1038/ ajg. 2013.218.

[16] Banks PA and Freeman ML. Practice guidelines in acute pancreatitis. Am J G.2006:101(10):2379-2400.

[17] Van Baal MC, Besselink MG, Bakker OJ, et al. Timing of cholecystectomy after mild biliary pancreatitis: a systematic review. Ann Surg.2012;255(5):860-866.

[18] Randial Perez LJ, Fernando Parra J, Aldana Dimas G. The safety of early laparoscopic cholecystectomy ( $<48$ hours) for patients with mild gallstone pancreatitis: a systematic review of the literature and meta-analysis. Cir Esp. 2014;92(2):107-113.
[19] Johnstone M, Marriott P, Royle TJ, et al. The impact of timing of cholecystectomy following gallstone pancreatitis. Surgeon. 2014;12(3):134-140.

[20] Da Costa DW, Bouwense SA, Schepers NJ, et al. Dutch Pancreatitis Study Group. Sameadmission versus interval cholecystectomy for mild gallstone pancreatitis (PONCHO): a multicentre randomized controlled trial. Lancet 2015; 386: 1261-1268.

[21] Noel R, Arnelo U, LundellL, et al. Index versus delayed cholecystectomy in mild gallstone pancreatitis: results of a randomized controlled trial. HPB (Oxford) 2018; 20: 932 938.

[22] Omar MA and Marwa N. Acute biliary pancreatitis - optimal time for cholecystectomy: a prospective randomized study. Clin Surg 2018; 3: 2151.

[23] Bakker OJ, van Santvoort HC, Hagenaars JC, et al. Timing of cholecystectomy after mild biliary pancreatitis. $\mathrm{Br} \quad \mathrm{J}$ Surg. 2011;98(10):1446-1454.

[24] Ito K, Ito $\mathbf{H}$ and Whang EE. Timing of cholecystectomy for biliary pancreatitis: do the data support current guidelines? J Gastrointest Surg. 2008;12(12):2164-217.

[25] Wilson CT and de Moya MA. Cholecystectomy for acute gallstone pancreatitis: early vs delayed approach. Scand J Surg. 2010 85(2):81-99.

[26] Alimoglu O, Ozkan OV, Sahin M, et al. Timing of cholecystectomy for acute biliary pancreatitis: outcomes of cholecystectomy on first admission and after recurrent biliary pancreatitis. World J Surg. 2003;27(3):256-259.

[27] Rosing DK, de Virgilio C, Yaghoubian A, et al. Early cholecystectomy for mild to moderate gallstone pancreatitis shortens hospital stay. J Am Coll Surg. 2007;205(6):762-766.

Citation: Abd El Aziz M, Zidan A, El Khawas M,El Sherbiny A, El Bahy A, Shoma A, El Moghazy M, Burham W. "Early Versus Delayed Laparoscopic Cholecystectomy in Mild Acute Biliary Pancreatitis. A Comparative Study”. ARC Journal of Surgery. 2021; 7(2):1-5. DOI: https://doi.org/ 10.20431/2455-572X.0702001.

Copyright: (ㅇ 2021 Authors. This is an open-access article distributed under the terms of the Creative Commons Attribution License, which permits unrestricted use, distribution, and reproduction in any medium, provided the original author and source are credited. 